ReVISTA DE LA ESCUELA DE CIENCIAS DE LA EdUCACIÓN, AÑo 17, NRO. 16, VOL. 1, ENERO A JUNIO DE 2021. PÁGINAS 68-76. ISSN 2362-3349 (EN LíNEA). JOHN DEWEY: LA EDUCACIÓN COMO PROCESO DE RECONSTRUCCIÓN DE EXPERIENCIAS. VICTORIA BARALDI.

\title{
JOHN DEWEY: LA EDUCACIÓN COMO PROCESO DE RECONSTRUCCIÓN DE EXPERIENCIAS
}

\author{
Victoria Baraldi * \\ Universidad Nacional del Litoral, Argentina \\ vbaraldi@gmail.com
}

Recibido: 13/07/2020 Aceptado: 25/10/2020

\section{Resumen}

John Dewey fue considerado uno de los filósofos y pedagogos más importantes de la primera mitad del siglo XX. Sus ideas continuaron desarrollándose en la filosofía, la psicología y la pedagogía y muchas de ellas siguen teniendo vigencia en la actualidad.

El presente artículo invita a la lectura de un conjunto de sus libros, retoma conceptos específicos de su perspectiva pedagógica y hace especial hincapié en la noción de experiencia que, de algún modo, sintetiza su pensamiento educativo. El texto pretende reconocer los elementos que, según Dewey, permiten constituir una experiencia en su impronta vital y reflexiva. Para llegar a este punto, primero se hace alusión al sentido que el autor le otorga a la filosofía y luego se describen los rasgos principales del movimiento de la Escuela Nueva al cual perteneció.

Los textos de Dewey fueron reinterpretados de acuerdo a distintos horizontes de lectura. Aquí se sostiene que sus ideas siguen teniendo vigencia, son relevantes para colocarse en torno a los rasgos que constituyen nuestro tiempo y, por consiguiente, pueden darle nuevos sentidos a la educación.

Palabras clave: John Dewey - Educación - Experiencia - Democracia.

\section{JOHN DEWEY: EDUCATION \\ AS A PROCESS OF RECONSTRUCTION OF EXPERIENCES}

\begin{abstract}
John Dewey was considered one of the most important philosophers and educators of the first half of the 20th century. His ideas were also developed in philosophy, psychology and pedagogy, and many of them are still current nowadays.

\footnotetext{
*Profesora en Ciencias de la Educación (UNER), Mg en Didácticas Específicas (UNL), Dra. en Educación (UNER). Profesora Titular Ordinaria de Didáctica General (FHUC-UNL). Profesora Adjunta ordinaria de Didáctica II (UNER- en uso de licencia). Directora de la Maestría en Docencia Universitaria (UNL). Directora de proyectos de investigación y de extensión.
} 
ReVISTA de LA ESCUELA DE CIENCIAS de LA EdUCACIÓN, AÑo 17, NRO. 16, VOL. 1, ENERO A JUNIO de 2021. PÁGINAS 68-76. ISSN 2362-3349 (EN LínEA). JOHN DEWEY: LA EDUCACIÓN COMO PROCESO DE RECONSTRUCCIÓN DE EXPERIENCIAS. VICTORIA BARALDI.

This article invites the reading of a set of his books. It also takes up some specific concepts from his pedagogical perspective and focus special attention on the notion of experience that, in some way, summarizes his educational thinking. The text tries to recognize the elements that, according to Dewey, allow to build an experience in its vital and reflective mark. In order to reach this point, first reference is made to the author's sense of philosophy, and then the main features of the New School movement to which he belonged are described.

Dewey's texts were reinterpreted according to different reading horizons. Here it is argued that their ideas are still valid and that they are relevant to place themselves around the features that our time requires and so, they can provide new meanings to education.

Keywords: John Dewey - Education - Experience - Democracy.

\section{Introducción. Volver a leer a Dewey}

Hay textos que vuelven a nosotros, quizás porque nos fueron presentados por alguien con quien tuvimos un especial afecto o por la circunstancia en la cual los leímos por primera vez. Pero vuelven, por sobre todas las cosas, porque siguen teniendo resonancia. John Dewey, uno de los principales filósofos y pedagogos del siglo XX, es uno de esos autores que vuelven una y otra vez. Es un "clásico", si por clásico entendemos a aquellos autores que generan empatía, que no pierden vigencia y que, generalmente, conjugan más de un campo disciplinar.

John Dewey (1859-1952) desarrolló un valioso pensamiento pedagógico. Entendemos por tal, junto a Bertha Orozco (2009), a un pensamiento teórico multirreferencial y complejo, que no se subsume a distintas disciplinas, pero que dialoga con ellas - como por ejemplo psicología, sociología, filosofía, antropología...- para analizar el objeto educación en su complejidad. Dewey pudo pensar la complejidad de lo educativo, porque contó con las herramientas de distintos campos de conocimiento y sostuvo una actitud de asombro y de implicación respecto al tiempo que lo tocó vivir. Sus textos expresan esta posición y compromiso ya sea como filósofo, como ciudadano o como educador. Consideró a la educación, no solo como una herramienta para la transmisión de valores culturales sino, fundamentalmente, como herramienta de transformación y crecimiento individual y social. Aspiraba a comprender su tiempo, no como observador pasivo, sino cuestionando todo aquello que ameritaba ser cambiado. El desarrollo de su pensamiento filosófico-pedagógico, fue simultáneo a su tarea docente y a su acción política. Como intelectual se manifestaba acerca de los temas del momento y participaba de actividades sociales y gremiales ${ }^{1}$.

A pesar de la amplitud de su pensamiento muchas veces se lo identifica a Dewey por la cuestión metodológica de la enseñanza, sin advertir que esas definiciones son derivaciones de una perspectiva filosófica y política. Al no reconocer las referencias de su pensamiento, dichos planteos quedan reducidos a una cuestión técnica que sesga el espíritu de su perspectiva.

Uno de los propósitos de este texto es poder reconocer por qué para Dewey la educación es una reconstrucción de la experiencia. Para llegar a esta idea, primero y a partir del libro La reconstrucción de la filosofía (1986) realizamos una aproximación al sentido, los límites y posibilidades que le otorga a la filosofía. Luego nos referimos al movimiento de la Escuela Nueva, haciendo hincapié en un conjunto de condiciones que hicieron posible la emergencia de este movimiento y señalando una serie de rasgos comunes entre los representantes de este movimiento, del cual formó parte nuestro autor. Allí nos detenemos -brevemente- en una noción de tiempo expresada por un filósofo vitalista. En tercer lugar, mencionamos el énfasis que puso Dewey para desterrar los falsos binarismos, y mencionamos tres ejemplos que aún persisten en los sistemas educativos. Para finalizar, nos centramos en su concepto de experiencia, en el que sintetiza su perspectiva filosófico-educativa y en el que expresa su concepción acerca del tiempo. No es pretensión del artículo dar cuenta de la totalidad de la obra de Dewey, sino retomar un conjunto de ideas que estimamos son potentes para pensar y proyectar el sentido de la educación hoy.

\section{La reconstrucción de la filosofía}

La reconstrucción de la filosofía fue publicada por primera vez en 1920 con el propósito de editar las conferencias dadas por Dewey en Tokio con anterioridad. Es un texto de síntesis, pues retoma desarrollos conceptuales ya expuestos en otros textos, tales como la relación entre Democracia y Educación, de 1916, o el interés y énfasis en reconocer los modos de producción del conocimiento científico, cuestión de capital importancia tanto para la filosofía como para la educación, tratado especialmente en Cómo pensamos, de 1910. Aquí ya hace alusión a la noción de experiencia, que luego profundiza en El arte como experiencia de 1934 y

\footnotetext{
${ }^{1}$ Existen muchas reseñas de la vida de John Dewey. Por ejemplo, Lorenzo Luzuriaga-pedagogo español exiliado en Argentina durante el franquismo- fue estudioso y difusor de sus ideas. En el marco de sus estudios identificó 38 libros y más de 100 artículos, escritos por él. También señala que se desempeñó en todos los niveles del sistema educativo. Fue profesor en distintas universidades de Estados Unidos e invitado a dar conferencias en distintas ciudades del mundo. Cfr. Luzuriaga, L. (1954).
} 
ReVISTA DE LA ESCUELA DE CIENCIAS DE LA EdUCACIÓN, AÑo 17, NRO. 16, VOL. 1, ENERO A JUNIO DE 2021. PÁGINAS 68-76. ISSN 2362-3349 (EN LíNEA). JOHN DEWEY: LA EDUCACIÓN COMO PROCESO DE RECONSTRUCCIÓN DE EXPERIENCIAS. VICTORIA BARALDI.

en Experiencia y Educación, de 1938. En todos los textos consultados aparece su preocupación educativa, ya iniciada en El niño y el programa escolar, de 1902 y el cometido dado a la formación de docentes implícito en la mayoría de sus textos y con mayores argumentos en La ciencia de la educación de 1929.

En La reconstrucción de la filosofía (1986) analiza con claridad el mundo en el que comenzó a desarrollarse la filosofía occidental. Comprende su emergencia y sus vínculos con el arte, la religión y la política. Sostiene que la filosofía no surgió como producto de una materia intelectual, sino de una materia social y emotiva. Señala los límites temporales y espaciales en los que se desarrolló la filosofía en la antigüedad y las derivaciones que dichos límites tuvieron en la cosmovisión de ese tiempo. Para Dewey la filosofía surge de los problemas humanos y está ligada a ellos. Por eso, cuando en segundo término analiza el surgimiento de la filosofía moderna, hace especial hincapié en las transformaciones sociales, políticas, religiosas y científicas que la precedieron y de las cuales la filosofía moderna se nutrió. Es decir, trabaja desde el supuesto de que:

la tarea característica, los problemas y la materia de la filosofía surgen de las presiones y reacciones que se originan en la vida de la comunidad misma en que surge una filosofía determinada y que, por tal razón, los problemas específicos de la filosofía varían en consonancia con los cambios que se producen constantemente en la vida humana, los que, en determinados momentos, dan lugar a una crisis y forman un recodo en la historia de la humanidad (Dewey, 1986, p.10).

A partir de esta afirmación, invita a dos grandes tareas para la filosofía. Por un lado, comprender los motivos que hicieron posible las trasformaciones de la filosofía en distintos períodos históricos -cuestión que él aborda en estas conferencias-; por otro lado, la necesidad de reconstruir la filosofía, tarea que invita a realizar en los últimos capítulos. En la introducción que agrega a la reedición de 1948 nos dice:

(...) la reconstrucción no puede ser menos que la tarea de desarrollar, de formar, de producir (en el sentido literal de este vocablo) los instrumentos intelectuales que habrán de llevar de una manera progresiva la investigación hacia las realidades profunda y totalmente humanas -es decir, morales- de la situación y del panorama de nuestro tiempo (Dewey, 1986, p.27).

En el marco del análisis de las transformaciones de la filosofía en la modernidad resalta la figura de Francis Bacon (1561-1626) a quien considera el precursor del espíritu de la vida moderna, no tanto por sus realizaciones prácticas sino por su figura destacada en la vida intelectual como "profeta de nuevas tendencias". El nuevo método de Bacon daba una importancia exageradamente pequeña al cuerpo de verdad ya existente y demostraba tener un sentido muy despierto de la extensión e importancia de las verdades que quedaban por alcanzar. La suya sería una lógica para descubrir, no una lógica para argumentar, demostrar y persuadir. Para Bacon, la vieja lógica, aun en sus mejores momentos, sería para enseñar lo ya conocido y el enseñar equivalía a adoctrinamiento, a hacer prosélitos. Por el contrario, "Bacon, (...) proclama con elocuencia la superioridad del descubrimiento de hechos y de verdades nuevas sobre la demostración de las verdades ya conocidas" (p.66). Éste es el espíritu que acompaña a Dewey en su producción filosófica.

Luego de explicar la interdependencia entre la revolución científica y la revolución industrial, advierte que, si bien contamos con un mayor dominio de la naturaleza, dicho dominio no es aplicado de una manera sistemática y preeminente al alivio de la situación del hombre y se pregunta “¿Dónde está el progreso moral que debería corresponder a nuestras grandes realizaciones económicas?” (p.126) Pregunta que hasta hoy no tiene una cabal respuesta².

Los últimos capítulos de este libro invitan a una reconstrucción de la filosofía con las herramientas metodológicas que propone el pragmatismo y la recuperación de los métodos científicos para la construcción del conocimiento ${ }^{3}$. También hace reconceptualizaciones en torno a nociones de experiencia y de razón, de lo ideal y lo real. Recordemos que uno de sus propósitos es la superación de los binarismos, cuestión que analizaremos más adelante. Pero primero, nos detendremos en el movimiento de la Escuela Nueva, en tanto las experiencias educativas que realizó Dewey fueron contemporáneas a otras experiencias desarrolladas en distintas ciudades de Europa, y mantienen rasgos en común.

\section{El movimiento de la Escuela Nueva}

Para poder comprender el movimiento de la Escuela Nueva, es importante reconocer el momento social y político en el cual surge, como así también las influencias filosóficas que recibió. Si bien este movimiento

\footnotetext{
${ }^{2}$ El desfasaje sufrido por una idea reducida del desarrollo, ha sido uno de los motivos de la policrisis que tenemos hoy en día y que es estudiada en profundidad por Morin y Kern B (2006).

${ }^{3}$ El interés en torno a los procesos de construcción en las ciencias, lo desarrolla con mayor exhaustividad en el libro Como pensamos (1989) en donde considera que existe una estrecha relación entre la curiosidad del niño, su fértil imaginación y el amor a la investigación experimental y la actitud del espíritu científico. Se trata de conocer con mayor exhaustividad los procesos de construcción del conocimiento científico para plantear situaciones análogas en el ámbito escolar.
} 
ReVISTA de LA ESCUELA DE CIENCIAS de LA EdUCACIÓN, AÑo 17, NRO. 16, VOL. 1, ENERO A JUNIO de 2021. PÁGINAS 68-76. ISSN 2362-3349 (EN LínEA). JOHN DEWEY: LA EDUCACIÓN COMO PROCESO DE RECONSTRUCCIÓN DE EXPERIENCIAS. VICTORIA BARALDI.

se expresa en el siglo $X X$, es posible pensar que ese siglo fue una concreción de transformaciones que fueron pensadas en el siglo XVIII y que se comenzaron a establecer en el siglo XIX. Una de estas está dada por los cambios relativos al rol de la mujer, cambios que se manifestaron en el vestir, el control de la natalidad, del médico en el parto, salidas fuera del hogar e inclusión en otros ámbitos laborales -aunque siempre con menores remuneraciones. Además de los nuevos desplazamientos de la mujer fuera del hogar, la emergencia del higienismo implicó ámbitos específicos para la crianza de los niños. Con posterioridad, la Primera Guerra Mundial, con la consiguiente baja de fuerzas de trabajo masculinas, se suma a los factores que implicaron modificaciones en las referencias teóricas y situaciones concretas respecto de la educación. Recordemos que se estaba en presencia de nuevos modos de producción, denominado esto por algunos autores como capitalismo de hierro, lo cual implicó cambios sustanciales en la vida doméstica y en las relaciones interpersonales. Un capitalismo que enajenaba a las personas, fragmentaba y controlaba sus tiempos en pos de una mayor productividad.

Desde el punto de vista de las ideas, un antecedente insoslayable al movimiento de la Escuela Nueva, fue el pensamiento de Juan Jacobo Rousseau (1712-1778), quien, con su teoría del hombre natural, propicia el desenvolvimiento de las condiciones vitales del hombre a través de una educación en directa relación con la Naturaleza durante la infancia y hasta la pubertad del niño. Su idea expresada en el Emilio en 1762 "el hombre nace bueno, la sociedad lo pervierte" es el sustrato de un desarrollo posible en libertad, con amor y asentado en la actividad. El niño dejará de considerarse un hombre pequeño, para ser comprendido como un ser con características propias.

Otro antecedente lo constituye la obra de Pestalozzi (1746-1827), quien se centra en la búsqueda de un alcance armónico entre el desarrollo individual y la formación social de los alumnos. Este pedagogo ginebrino se propuso educar al mayor número de niños, en especial a los de condición social de menores ingresos. Realizó diversas experiencias en donde albergó a los niños pobres y huérfanos. Tomó a la vida campesina como nuevo ámbito de aprendizaje y resaltó la importancia del aprendizaje de oficios otorgando importancia a la formación laboral. Su cónyuge fue la principal colaboradora en sus emprendimientos. Su obra principal fue Como Gertrudis educa a sus hijos de 1801.

Otro precursor fue Froebel (1782-1852), pedagogo que enseñó desde muy joven en una escuela de Frankfurt. Fundador del Kindergarten o Jardín de niños, otorga importancia al sentido de lo lúdico en el niño. Propone la educación en un clima de libertad, creatividad y responsabilidad. Su libro principal fue La educación del hombre de 1826.

Sara Alí Jafella (2006) además de marcar estas referencias filosóficas específicas, considera que el movimiento de la Escuela Nueva estuvo influido por nuevas corrientes de pensamiento, tales como el romanticismo expresado en la filosofía (Herder, Fitche, Schelling) y la literatura alemana (Goethe), el vitalismo (Henri Bergson) y el pragmatismo (Wiiliam James, Pierce). Este último movimiento fue el que tuvo mayor desarrollo en Estados Unidos y al cual Dewey perteneció.

Las expresiones concretas de esta nueva corriente pedagógica, se fueron dando tanto en Europa como en Estados Unidos. Diversos textos de historia y filosofía de la educación resaltan un conjunto de representantes de este movimiento, muchos de los cuales tenían una formación inicial en otras disciplinas y luego se inclinaron a la educación. Este fenómeno aconteció también en otros momentos de la historia de la educación, pues grandes pedagogos tuvieron su formación inicial en filosofía, biología, psicología, arte.

Entre los nombres más reconocidos, y tomando reconstrucciones realizadas por distintos estudiosos ${ }^{4}$, podemos mencionar los siguientes: el neurólogo suizo Édouard Claparède (1873-1940), quien procura establecer el carácter científico de la psicología y fundador del Instituto Rousseau en 1912; el médico belga Ovide Decroly (1871-1932) reconocido por la importancia que le otorga al juego, y por su propuesta de los centros de interés y el método de la lectura global; la primera doctora egresada en 1911 de la Universidad de Roma, María Montessori (1870-1942) conocida por sus trabajos en distintos países, y por la importancia otorgada a los muebles y los materiales didácticos para el aprendizaje de los niños; al pedagogo francés Roger Cousinet (1881-1973) a quien se lo reconoce por su metodología de enseñanza a través del trabajo por equipos y también por la importancia otorgada al juego; a Celestin Freinet (1896-1966) se lo tiene aún presente por la inclusión de la imprenta en la escuela, y la posibilidad de que los alumnos publicaran sus experiencias en diversos campos del saber. Por su parte, Kerschensteiner (1854-1932) en Alemania, con sus escuelas basadas en el trabajo, y Antón Makarenko (1988-1939), con su gran obra realizada en la Rusia post zarista dedicada a formar el hombre nuevo derivado de la revolución de 1917, se suman a una constelación de experiencias diversas y complementarias en el viejo mundo. Dewey desarrolló su teoría en Estados Unidos, pero también fue invitado por diversos países tales como Japón, China, Turquía, Unión Soviética, México, Francia, Escocia para exponer sus ideas pedagógicas.

A pesar de estos múltiples proyectos que se implementaron y los textos que se escribieron, los principios de la Escuela Nueva no lograron establecerse cabalmente en los sistemas educativos. Muchos de sus postulados tuvieron vigencia en proyectos educativos aislados. El nivel inicial es el que más incorporó los propósitos centrales de este movimiento.

\footnotetext{
${ }^{4}$ Además del texto de Sara Alí Jafella hemos consultado Luzuriaga (1961).
} 
ReVISTA DE LA ESCUELA DE CIENCIAS DE LA EdUCACIÓN, AÑo 17, NRO. 16, VOL. 1, ENERO A JUNIO DE 2021. PÁGINAS 68-76. ISSN 2362-3349 (EN LíNEA). JOHN DEWEY: LA EDUCACIÓN COMO PROCESO DE RECONSTRUCCIÓN DE EXPERIENCIAS. VICTORIA BARALDI.

Si bien cada uno de los autores mencionados tuvo sus propias perspectivas, es posible reconocer un conjunto de características comunes. En primer lugar, el reconocimiento de la niñez como un momento particular de la vida. El niño no es visto como un ser incompleto o un ser carente que se transformará en adulto, sino como un ser con características específicas. La consideración de la infantilidad ocupa un lugar central en estas experiencias educativas. Es lo que algunos autores han denominado construcción social de la infancia ${ }^{5}$. En el niño y el programa escolar, Dewey describe las características del mundo infantil o mejor dicho cómo el niño ve al mundo, cuestión central como punto de partida para organizar la enseñanza.

Otro de los ejes del movimiento de la Escuela Nueva es la vitalidad, en estrecha conexión con el vitalismo como movimiento filosófico. Dentro de esta corriente filosófica merecen un párrafo aparte, los planteos de Henri Bergson (1859-1941) respecto al tiempo, pues se oponían a los conceptos vigentes en las ciencias exactas y naturales. Bergson no solo polemizó con Kant respecto de la concepción de tiempo, sino que lo hizo con Einstein quien sostenía una noción desde el punto de vista de su teoría científica.

Bergson se opone a la manera en que desde las ciencias exactas se comprendía al tiempo y sostiene que al verdadero tiempo no hay que medirlo matemáticamente, ni dividirlo mecánicamente, porque para el ser humano éste fluye como una corriente continua, una duración. Bergson rebautiza al tiempo con el nombre de "durée" pues le critica a la tradición el haberlo confundido con el espacio, considerado homogéneo, mensurable y divisible. Por el contrario, según él es heterogéneo continuo, e indivisible. Cherniasvky (2006), al estudiar esta noción en Bergson, señala que la durée va recibiendo distintos atributos en las expresiones de su obra tales como creación, indivisibilidad, continuidad, sucesión, interpenetrabilidad de las partes, movimiento, dinamismo, novedad, heterogeneidad, imprevisibilidad, irreversibilidad. Pero los atributos más importantes son los de constitución, continuidad y sucesión 6 . Luego de hacer un análisis exhaustivo entre la noción de tiempo de Bergson y de otros filósofos que lo precedieron plantea que:

La originalidad de Bergson consiste en poner el acento en un determinado tiempo, lo cual significa un movimiento doble bien preciso: privilegiar el tiempo de la vida por sobre el tiempo de la ciencia, y, consecuentemente, darle la dimensión ontológica que hace depender al resto de los problemas de él. La novedad de Bergson es que se concentra fundamentalmente en el tiempo de la vida. Se concentra: hace del tiempo de la vida el centro de su filosofía (Cherniasky, 2006, p.19).

En la segunda década del siglo XX la revisión de las nociones acerca del tiempo también se hizo presente en la literatura. Tomas Mann a través Hans Castorp, personaje principal de la novela La Montaña Mágica, pone en palabras los distintos modos de percibir el tiempo según el lugar en donde reside y las acciones que realiza. A su vez, Mann no pierde oportunidad a lo largo de esta extensa novela de introducir profundas y variadas reflexiones filosóficas en torno a este.

Lo cierto es que, en las experiencias educativas de la Escuela Nueva, se comenzó a concebir el tiempo de otro modo. En una de ellas, realizada en la ciudad de Rosario por las hermanas Olga y Leticia Cossettini, entre los años 1935- 1950 una de las egresadas de esa escuela comienza recuerda la experiencia diciendo: "era una escuela sin filas y sin campanas", porque la jornada escolar se organizaba a través de experiencias vitales $^{7}$. En los relatos de sus docentes y estudiantes se pueden reconocer todos los elementos que estamos caracterizando, siendo la vida en comunidad y la vinculación entre escuela y barrio un componente central de esa experiencia educativa.

Para Dewey la noción de vitalidad está siempre, pues considera que “... la unidad de la nueva pedagogía se encuentra en la idea de que existe una íntima y necesaria relación entre los procesos de la experiencia real y la educación" (Dewey, 1960a, p16). Por eso centrará la necesidad de tener una "idea correcta de la experiencia". En su perspectiva es central la idea de un tiempo vital, la educación educa para el presente, sin desconocer el pasado y con dirección al futuro. Luego veremos cómo este tiempo vital se hace presente en su consideración de la experiencia.

Un tercer rasgo de la Escuela Nueva es la actividad. Learning by doing, o aprender haciendo, fue un lema importantísimo. Dewey es muy crítico con algunos planteos de algunas escuelas progresistas, que pregonaban la actividad por la actividad misma, a lo cual contrapone el concepto de experiencia que desarrollaremos en la última parte de este artículo.

\footnotetext{
${ }^{5}$ Una excelente reconstrucción de los sentidos dados a la infancia a fines del siglo XIX y principio de siglo XX está presentado en el libro de Carli, (2012). Si bien el texto busca focalizar en los discursos de la infancia en la educación argentina, se exponen distintas concepciones que circularon en otros ámbitos académicos.

${ }^{6}$ Continúa diciendo: "La durée constituye, es decir, crea, produce novedad, innova. Por eso es irreversible e imprevisible. Porque sorprende con un futuro inasimilable al pasado. Sus partes se distinguen entre sí, son distintas, heterogéneas. Pero estas partes, por más heterogéneas que sean entre sí, no merecen ni siquiera ser llamadas partes, pues se interpenetran, se confunden, esfuman sus límites hasta volver a la durée indivisible y continua. La sucesión, es finalmente el aspecto dinámico y móvil de la durée, su movimiento, su movilidad" (Cherniasky, 2006, pp. 2-3).

${ }^{7}$ Esta experiencia fue documentada por el cineasta rosarino Piazza (1991). También los fundamentos de la experiencia están editados en Cossettini, O. (1935).
} 


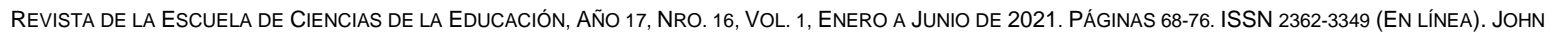
DEWEY: LA EDUCACIÓN COMO PROCESO DE RECONSTRUCCIÓN DE EXPERIENCIAS. VICTORIA BARALDI.

La libertad y la vida en comunidad, completan las particularidades de este modo de educar. El niño tiene capacidad para elegir, de autorregularse. Pero, además, necesita aprender con otros, pues la escuela es un ámbito vital y como tal, es parte de la sociedad, con la cual tiene que convivir.

Con respecto a la libertad, Dewey aclara que "la única libertad de importancia durable es la libertad de la inteligencia, es decir, la libertad de observación y de juicio ejercida, respecto de propósitos que tiene un valor intrínseco" (Dewey, 1960a, p.77). Advierte que el error más común es identificar la libertad con la libertad de movimiento o el aspecto físico. Estos aspectos son medios necesarios para otro tipo de libertad, y no pueden ser fines en sí mismos.

\section{Hacia la disolución de los falsos binarismos}

Uno de los propósitos de la filosofía de Dewey fue la superación de los falsos binarismos. En sus trabajos se pueden observar las constantes relaciones que establece entre el conocer y el hacer, el trabajo y el ocio, el hombre y la naturaleza. Nos detendremos -muy brevemente- en tres binarismos con larga data en educación.

-Individuo-social. La importancia de la vida democrática.

Dewey se oponía a la dicotomía individuo-sociedad. Lo que el individuo es, está constituido en parte por el tipo de comunidad en la que participa. Hace una defensa de la vida en comunidad, y de una comunidad democrática, a la cual considera que es más que una forma de gobierno, sino un modo de vivir asociado.

Una sociedad es democrática en la medida en que facilita la participación en sus bienes de todos sus miembros en condiciones iguales y que asegura el reajuste flexible de sus instituciones mediante la interacción de las diferentes formas de vida asociada. (Dewey, 1995, p.91).

Este ideal democrático es el norte de su filosofía educativa: la democracia educa y la educación democratiza.

-El niño y el programa escolar. Así apareció traducido en Argentina, el texto The child and the curriculum, publicado en 1902 en el que hace referencia a dos grandes contiendas o "sectas pedagógicas", según sus palabras. Unas, centradas en la importancia de las materias del programa, otras, centradas en el niño. Sin desconocer las diferencias entre el mundo personal del niño y el mundo impersonal de los programas, la unidad que presenta el primero y las múltiples especializaciones del segundo; lo emotivo y práctico de la vida infantil y lo lógico y abstracto de los programas, lejos de "optar" prioritariamente por uno u otro, Dewey considera que son dos elementos necesarios de ser conjugados, puestos en relación. Ante esto dice: las materias tienen que ser psicologizadas, introducidas en el campo de la vida infantil, porque es nociva la idea de que existe un abismo entre la experiencia del niño y las materias que constituyen un programa escolar.

Del lado del niño el problema estriba en ver cómo su experiencia contiene dentro de sí misma elementos -hecho y verdades- justamente de la misma naturaleza que los que constituyen la materia de estudio ya elaborado; y, lo que es más importante, cómo contiene en sí misma, las actitudes, los motivos y los intereses que han operado el desarrollo y la organización de las materias hasta el plano que ocupan ahora. Del lado de las materias, el problema consiste en interpretarlas como manifestaciones de fuerzas que actúan en la vida del niño, y en descubrir los procesos que intervienen entre la experiencia presente del niño (Dewey, 1954, p.32).

-Sentimiento y pensamiento. En el marco del proceso de elaboración de una teoría estética, Dewey también articula sus ideas en pos de conjugar falsos binarismos, que se dan también en el arte, como por ejemplo la separación entre sustancia y forma. Para abordar la cuestión estética lo hace desde la noción de experiencia. En uno de los capítulos se refiere al acto expresivo y allí remarca la indisociable relación entre sentimiento y pensamiento.

Solamente la psicología que separa las cosas que en realidad se pertenecen entre sí, sostiene que los científicos y los filósofos piensan, mientras que los poetas y los pintores siguen sus sentimientos. En ambos, en la extensión y grado en que son de rango comparable, existe un pensamiento emocionalizado y hay sentimientos cuya sustancia consiste en significaciones e ideas (Dewey, 1949, p. 66).

Individuo y sociedad, curriculum y mundo infantil, sentimiento y pensamiento son sólo algunos de los tantos binarismos que Dewey procuró articular. 
ReVISTA DE LA ESCUELA DE CIENCIAS DE LA EdUCACIÓN, AÑo 17, NRO. 16, VOL. 1, ENERO A JUNIO DE 2021. PÁGINAS 68-76. ISSN 2362-3349 (EN LíNEA). JOHN DEWEY: LA EDUCACIÓN COMO PROCESO DE RECONSTRUCCIÓN DE EXPERIENCIAS. VICTORIA BARALDI.

\section{La educación como reconstrucción de la experiencia}

En los últimos tramos de su producción dos textos analizan nuevamente y con mayor detalle la noción de experiencia: El arte como experiencia, en el marco de la elaboración de una teoría estética, y Experiencia y Educación, en donde retoma planteos anteriores y da mayor precisión a elementos que la componen.

Dewey ya se había diferenciado de los modos en que tanto la filosofía clásica como el empirismo inglés habían considerado a la experiencia. A ambas perspectivas las había procurado comprender atendiendo a los límites de los contextos en habían tenido lugar. Él tiene otra mirada y, para este concepto en particular, retoma nociones de la biología que le permiten explicar que el organismo actúa sobre las cosas que lo rodean valiéndose de su propia estructura, y que los cambios que produce en ese medio reaccionan a su vez sobre el organismo y sus actividades. En la reconstrucción de la filosofía había dicho:

El ser viviente padece, sufre, las consecuencias de su propio obrar. Esta íntima conexión entre el obrar y el sufrir o padecer es lo que llamamos experiencia. El obrar y el sufrir, desconectados el uno del otro, no constituyen ninguno de las dos experiencias (Dewey, 1986, p.110).

\section{Y, en Democracia y Educación, había señalado que:}

La naturaleza de la experiencia sólo puede comprenderse observando que incluye un elemento activo y otro pasivo peculiarmente combinados. Por el lado activo, la experiencia es ensayar un sentido que se manifiesta en el término conexo "experimento". En el lado pasivo es sufrir o padecer (Dewey, 1995, p.124).

En Democracia y Educación expresa su concepción de educación como reconstrucción o reorganización de la experiencia y aclara que esta reconstrucción puede ser tanto social como personal. De este modo se diferencia de otras acepciones que entienden a la educación como preparación para un futuro remoto, como desenvolvimiento, como formación externa o como recapitulación del pasado.

En El arte como experiencia se propone construir una teoría estética. Comienza por criticar a los museos y al acopio de las obras de arte como demostración de riqueza, cuestiones asociadas al capitalismo. Argumenta en este texto que el problema es recobrar la continuidad de la experiencia estética con los procesos normales de la vida y descubrir la senda por la cual estas obras idealizan cualidades que se encuentran en la experiencia común.

Dewey piensa que lo estético no es una intrusión a la experiencia, sino que es el desarrollo intenso y clarificado de los rasgos que pertenecen a toda experiencia completa y normal y esa es la base para construir su teoría estética. "Para ser verdaderamente artística, una obra debe ser estética, es decir, hecha para ser gozada en la percepción receptiva (...) En suma, el arte, en su forma, une la relación misma de hacer y de padecer, la energía que va y viene, lo que hace que una experiencia sea una experiencia” (Dewey, 1949, p.45).

En Experiencia y educación, aclara que una experiencia puede ser educativa, pero también puede ser antieducativa, porque puede predisponer negativamente a experiencias futuras, es decir detener o perturbar el desarrollo de otras ulteriores. El agrado o desagrado de la experiencia vivida tendrá influencia en experiencias ulteriores. A esto se refiere en uno de los principios de la experiencia: la continuidad, es decir el modo que la experiencia vivida influye o predispone para experiencias futuras. "El principio de continuidad de la experiencia significa que toda experiencia recoge algo de la que ha pasado antes y modifica de algún modo la cualidad de lo que viene después" (Dewey, 1960ª , p.37). "Cada experiencia es una fuerza en movimiento. Su valor sólo puede ser juzgado sobre la base de aquello hacia lo que se mueve" (Dewey, 1960, p.41).

Es en el principio de continuidad que se hace presente un aspecto de la temporalidad que, en el marco de un tiempo vital en movimiento, acentúa la relación presente-futuro y apunta a uno de los problemas centrales de una educación basada en la experiencia, que es "seleccionar aquel género de experiencias presentes que vivan fructífera y creadoramente en las experiencias subsiguientes" (Dewey, 1960, p.25). El futuro aquí aparece como dirección, no obstante, Dewey insiste en el tiempo presente y reniega de otras perspectivas que entienden a la educación como "preparación" para el futuro. Por eso aclara:

Vivimos siempre en el tiempo que vivimos y no en algún otro tiempo, y sólo extrayendo en cada tiempo presente el sentido pleno de cada experiencia presente nos prepararemos para hacer la misma cosa en el futuro. Esta es la única preparación que a la larga cuenta para todos. (Dewey, 1960, p.59).

Por otra parte, para que exista experiencia tiene que darse una situación en donde un individuo realiza interacciones con el ambiente. La interacción es el segundo principio que permite interpretar la función y fuerza educativa de una experiencia. Se trata del juego recíproco de las condiciones objetivas y las internas que, tomadas juntas, o en su interacción, constituyen una situación. Las concepciones de situación y de interacción son inseparables una de otra. Una experiencia es siempre lo que es porque tiene lugar una transacción entre un individuo y lo que, en el momento, constituye su ambiente. Fruto de esta transacción ambos salen 
ReVISTA de LA ESCUELA DE CIENCIAS de LA EdUCACIÓN, AÑo 17, NRO. 16, VOL. 1, ENERO A JUNIO de 2021. PÁGINAS 68-76. ISSN 2362-3349 (EN LínEA). JOHN DEWEY: LA EDUCACIÓN COMO PROCESO DE RECONSTRUCCIÓN DE EXPERIENCIAS. VICTORIA BARALDI.

modificados. Los principios de continuidad e interacción no se pueden separar y están vinculados a los aspectos longitudinal y lateral de la experiencia.

Cuando Dewey se refiere a condiciones objetivas menciona un conjunto de elementos: las palabas del educador, los libros, los juegos, los juguetes, aparatos, materiales..., pero señala que lo más importante es la "total estructuración social de las situaciones en que se halla la persona" (Dewey, 1960, p. 53), esto es: el ambiente. Toda experiencia auténtica tiene un aspecto activo que cambia el ambiente. Esta selección de condiciones objetivas por parte del docente, requiere de la comprensión de las necesidades y capacidades de los individuos que están aprendiendo en un tiempo dado.

En este proceso de análisis y selección de experiencias, Dewey enfatiza que tenemos el problema de "descubrir la conexión que existe actualmente dentro de la experiencia entre los hechos del pasado y los sucesos del presente" (Dewey, 1960a, p.20). Aquí hay otra referencia temporal y ahora en la estrecha relación entre presente y pasado. Toda experiencia se da en un tiempo presente, pero los elementos que la constituyen ponen en evidencia una trama construida desde el pasado.

En otras palabras, el acertado principio de que los objetivos del aprender se hallan en el futuro y sus materiales inmediatos en la experiencia presente sólo puede ponerse en práctica en el grado en que se extienda la experiencia presente, como ella fue, hacia atrás. Sólo puede ampliarse al futuro en la medida que ha sido ampliada para penetrar en el pasado (Dewey, 1960, p.102).

Si bien solo vivimos un presente, ese presente se vincula con el pasado y se direcciona a un futuro. Teniendo en cuenta los vínculos presente-futuro y presente-pasado (por poner términos convencionales) será misión del educador redireccionar las experiencias, pues la experiencia es educativa cuando "el educador considera a la enseñanza y al aprender como un proceso continuo de reconstrucción de la experiencia" (Dewey, 1960, p.118). Con estos conceptos Dewey termina de articular las nociones de individuo y sociedad, pensamiento y acción, y abordar el presente en función del futuro y del pasado. Se trata de una síntesis que articula sus dimensiones psicológicas, sociales y filosóficas.

\section{Para finalizar y continuar...}

Iniciamos este artículo diciendo que Dewey es considerado por muchos autores como el filósofo y pedagogo más importante de la primera mitad del siglo XX. Sus ideas fueron retomadas en distintos campos de conocimiento. Sentó las bases de lo que luego fue el constructivismo, dio sustento a las principales perspectivas que en torno al aprendizaje circularon en el siglo XX, en particular, los enfoques basados en la resolución de problemas. Su perspectiva pedagógica permitió - junto a otras referencias- la elaboración y concreción de experiencias educativas alternativas.

Hoy, la noción de experiencia, esa suerte de síntesis de su pensamiento pedagógico, es vuelta a traer en las discusiones al calor de lo que algunas universidades denominan educación experiencial ${ }^{8}$ y sigue siendo una idea potente para la elaboración de nuevos proyectos educativos.

Hemos destacado el énfasis que da Dewey a la necesidad de vivir el presente, como así también el sentido que le dio a la democracia, pues en su concepción de sujeto, este está en parte constituido por la comunidad de la que forma parte. Una democracia entendida no -solo- como forma de gobierno, sino como forma de vivir asociado de modo tal que los bienes de cada sociedad, puedan ser compartidos por todos sus miembros.

Dewey ha sido reivindicado por diversos pedagogos en el siglo XX. En Argentina tuvo distintos momentos de recepción y horizontes de lectura, como así también momentos de silenciamiento ${ }^{9}$. En las últimas décadas, fue recuperado por el pedagogo norteamericano Henry Giraoux, quien comparte la idea de concebir a la escuela pública como esfera democrática y a los maestros como intelectuales. Conceptos centrales que permiten enmarcar la educación en la complejidad del presente.

Dewey enfatiza una y otra vez en la idea de reconstrucción. La filosofía se reconstruye al calor de las transformaciones sociales, culturales, científicas y la educación debería reconstruir las experiencias individuales y sociales para darles dirección. Y por eso es tan importante retomar estas premisas.

Hoy estamos viviendo una situación inédita que, generada por la pandemia del COVID-19, ha puesto en evidencia muchos elementos del pasado. Se trata de un fenómeno global vivido de diversos modos según edades, sexo y clase social, y también según las políticas sanitarias de cada país para mitigar el avance del virus. Al cierre de este texto, el mundo está asolado por escalofriantes números de contagios, enfermedades y muertes $^{10}$.

\footnotetext{
${ }^{8}$ La Universidad Nacional del Litoral incluye este concepto en el marco de las opciones para sustanciar la función de extensión. Una de las convocatorias tiene el nombre Proyectos de Extensión de Educación Experiencial.

${ }^{9}$ Un interesante artículo plantea que Dewey fue leído desde las primeras décadas del siglo XX en Argentina, pero con horizontes de lecturas bien distintas Cfr. Dussel y Caruso (1996).

${ }^{10} \mathrm{Al}$ momento de cerrar este artículo -13 de julio de 2020 - ya había más de 560.000 muertos a nivel mundial.
} 
ReVISTA DE LA ESCUELA DE CIENCIAS DE LA EdUCACIÓN, AÑo 17, NRO. 16, VOL. 1, ENERO A JUNIO de 2021. PÁGINAS 68-76. ISSN 2362-3349 (EN LíNEA). JOHN DEWEY: LA EDUCACIÓN COMO PROCESO DE RECONSTRUCCIÓN DE EXPERIENCIAS. VICTORIA BARALDI.

El origen del virus ha dado lugar a distintas hipótesis respecto de su surgimiento. Lo cierto es que acontece en un escenario mundial de múltiples crisis. Policrisis, es la palabra que emplea Morin para aludir a las crisis política, demográfica, ecológica, económica y del hábitat que se conjugan desde hace varias décadas, y que tiene entre sus sustratos - junto a otras explicaciones- unas cegueras de conocimiento. Crisis que ponen al descubierto las fuertes asimetrías e injusticias de la vida social. ¿Será esta situación de pandemia ocasión para interpelar nuestras formas de vida? ¿Podremos generar profundos ámbitos de reflexión y de participación para dar otra dirección a nuestro presente? ¿Se constituirá esta situación en experiencia social que pueda reivindicar la importancia de lo común y la importancia del cuidado?

Para dar cuenta de la necesidad de encontrar puntos de inflexión a estas múltiples crisis, son oportunas las palabras con que William Ospina cerró la conferencia inaugural del Congreso lberoamericano de Educación realizado en la ciudad de Buenos Aires en el año 2010:

A lo mejor los grandes paradigmas al cabo de cincuenta años, no serán como para nosotros el consumo, la opulencia, la novedad, la moda, el derroche, sino la creación, el afecto, la conservación, las tradiciones, la austeridad. Y a lo mejor ello no corresponderá ni siquiera a un modelo filosófico o ético sino a unas limitaciones materiales. A lo mejor lo que volverá vegetarianos a los seres humanos no serán la religión o la filosofía sino la física escasez de proteína animal. A lo mejor lo que los volverá austeros no será la moral sino la estrechez. A lo mejor lo que los volverá prudentes en su relación con la tecnología no será la previsión sino la evidencia de que también hay en ella un poder destructor. A lo mejor lo que hará que aprendan a mirar con reverencia los tesoros naturales no será la reflexión sino el miedo, la inminencia del desastre, o lo que es aún más grave, el recuerdo del desastre (Ospina, 2010, último párrafo).

\section{Referencias bibliográficas}

Ali Jafella, S. (2006). Travesías filosóficas y sociales de la "Escuela Nueva" en Europa y en Estados Unidos. La Plata: Ediciones al Margen.

Carli, S. (2012). Niñez, pedagogía y política. Buenos Aires: Miño y Dávila.

Cherniavsky Axel: La concepción del tiempo de Henri Bergson: El alcance de sus críticas a la tradición y los límites de su originalidad. En: Revista de Filosofía y Teoría Política, 2006 (37), pp.45-68. Recuperado de http://www.rfytp.fahce.unlp.edu.ar/.

Cossettini, O. (1935). Sobre un ensayo de Escuela Serena en la provincia de Santa Fe. Colección Biblioteca Pedagógica № 3. Santa Fe: Instituto Social de la Universidad Nacional del Litoral.

Dewey, J. (1949). El arte como experiencia. México: Fondo de Cultura Económica.

Dewey, J. (1954). El niño y el programa escolar. Buenos Aires: Losada.

Dewey, J. (1960a). Experiencia y educación. Buenos Aires: Losada.

Dewey, J. (1960b). La ciencia de la educación. Buenos Aires: Losada.

Dewey, J. (1986). La reconstrucción de la filosofía. Barcelona: Planeta- Agostini

Dewey, J. (1989). Como pensamos. Barcelona: Paidós.

Dewey, J. (1995). Democracia y educación. Una introducción a la filosofía de la educación. Madrid: Morata.

Dussel, I. y Caruso, M. (1996). Lecturas y lectores de Dewey en Argentina (1900/1950). En: Revista del Instituto de Investigación en Ciencias de la Educación. Miño y Dávila editores. Facultad de Filosofía y Letras. UBA Año V N.ำ 8, pp. 59-68.

Luzuriaga, L. (1954). Estudio preliminar. La pedagogía de John Dewey, en Dewey, J. El niño y el programa escolar. Buenos Aires: Losada.

Luzuriaga, L. (1961). Concepto de la Nueva Educación, en Métodos de la Nueva Educación, Buenos Aires: Losada.

Morin, E. y Kern, B. (2006). Tierra patria. Buenos Aires: Ediciones Nueva Visión.

Orozco, B. (2009). Saberes socialmente productivos y aprendizaje. Articulación didáctica pedagógica. En Gómez Sollano M. (coord.) Saberes socialmente productivos y educación. Contribuciones al debate. México: Universidad Nacional Autónoma de México.

Ospina, W. (2010). Conferencia inaugural del Congreso Iberoamericano de Educación. Buenos Aires: Metas 2021. Recuperado de http://metas2021.org/congreso/ospina.htm

Piazza, M. (1991). La escuela de la señorita Olga [cinta documental]. Argentina. Recuperado de https://www.youtube.com/watch?v=YJRzTcNWITY. 